\title{
Difficulties and Challenges of Strategic Management of Start-up Enterprises in the New Era
}

\author{
Yixue Zhao ${ }^{1, *}$ \\ ${ }^{1}$ School of Economics and Management, Lanzhou University of Technology, Lanzhou, Gansu Province, 730050, China
}

\begin{abstract}
Strategic management is a short- to long-term development plan concerning the goals of an enterprise. Formulating appropriate strategic management is of great and far-reaching significance for the current development and sustainable development of the enterprise There is no doubt that the formulation of strategic management is very important. In the new era, under the condition of rapid economic development, the way enterprises formulate strategies and the development of strategic formulation have very important research value. This paper thus examines the characteristics of strategic management and the process of strategic management, the current situation of the development of entrepreneurial enterprises in the new era, and then uses quantitative analysis to analyse the impact of the Midea group on the strategic management of enterprises, puts forward several issues and decisive factors that should be considered for strategic management, and puts forward important implications for the strategic management of entrepreneurial enterprises.
\end{abstract}

Keywords: strategic management; development planning; social responsibility; entrepreneurial enterprises; the new era

\section{Introduction}

In the period of rapid economic development, the development of enterprises has been actively leading the transformation and development from the beginning. In other words, uncertain factors such as the international situation of economic development have brought higher requirements for enterprises. Prior to this, the development of enterprises may be to create culture. He Faith attracts capital and registered company stakeholders to produce products or service sales to earn profits. This is the basis of enterprise development. However, as the industry has great momentum and capital inflows become more frequent, many companies have miraculously sprung up. Consumers are becoming more and more strict in their choices. This is definitely a big challenge for companies, and it seems to meet the requirements of the consumer market [1]. The direction of enterprise development is a general trend, but this is only a small part of the factors. The strategic choice environment of enterprises is becoming more and more complex, so it needs a comprehensive and coordinated development to improve their own capabilities, and enhance their own competitiveness. Corporate strategic management summarizes the development background and current situation of venture companies, the historical development of Chinese corporate strategic management, and then analyses the strategic management of Midea Group, as well as the problems of corporate and strategic management, and finally proposes the influence of diversified strategic development. Under the macro environment, enterprises can still maintain their core competitiveness and achieve the conclusion of sustainable development [2].

\section{Characteristics and processes of enterprise strategic management}

\subsection{Characteristics of strategy}

"War" refers to battle and war, "strategy" refers to strategy and plan. War in the sense of "strategy" has existed since antiquity and has multiple meanings depending on different application environments. From the perspective of corporate strategy, American experts published a famous theoretical article "Corporate strategy" in 1965. Since then, the word "strategy" has been included in the policy of enterprises. Sustainable development and profitability are the main development direction for the enterprise. Therefore, for an enterprise, strategy means both a strategy and a model, that is, according to the development trend of the enterprise, the strategy is a plan of what development the company wants toto achieve and how to achieve this development. For the process of enterprise development, strategy is a model. Enterprises need to plan what model to choose and what development path to take to ensure the survival of the enterprise in a difficult

\footnotetext{
* Corresponding author: $\underline{\text { mzhao320@163.com }}$
} 
environment. The typical features of corporate strategy are integrity, long-term nature, stability, feasibility and hierarchy. The so-called overall situation refers to the comprehensive consideration of all internal and external factors when an enterprise formulates its strategy not just for one department or one aspect. Strategy plays an important leading role in corporate organization and system. It is the main factor of the development of the entire system. The formulation of goals requires comprehensive consideration, and the achievement of such goals requires complex cooperation. Therefore, only based on a comprehensive perspective, we can promote the healthy development of enterprises. Formulating strategies according to a certain stage or a certain part of the goal will inevitably restrict the overall sound development of the enterprise. Long-term nature refers to the long-term development of the enterprise when an enterprise formulates its strategy. Strategy is divided into long-term strategy, medium-term strategy and short-term strategy. Long-term strategy is the goal that an enterprise must achieve within 5-10 years. The medium-term strategy is the direction formulated for 15 years, and the short-term strategy refers to the results that need to be achieved within one year. For enterprises, clear mid- and short-term goals serve as long-term goals. Therefore, various factors must be considered comprehensively, and the long-term goals must be established first; afterward, the goals are decomposed into annual plans. Once the stability requirement of the corporate strategy is established, it cannot be changed at will. No matter how the business environment changes, only companies that focus on resource development and sustainability can establish their own professionalism and obtain permanent and stable returns. Feasibility means that the strategy formulated by the company is in line with the development of the company rather than its imagination. Only in line with the development path of the enterprise, it can be a goal that can be sustained. In addition, the company's strategy formulation should conform to reality, proceed from reality, and be based on the company's internal resources rather than lagging behind closed doors. The hierarchy is related to identity. Strategy can be divided into many parts. Each part represents a different part of the strategy, there is no level, only high and low points. Together they form and influence the same strategy. In a hierarchical structure, it generally means that the upper layer guides the next layer, and the next layer supports the upper layer.

\subsection{The process of enterprise strategic management}

\subsubsection{Strategic management analysis}

The first and the most important step of strategic management is to assess the state of the enterprise according to the joint action of internal factors and external environment [3]. It is also an important step for an enterprise to understand itself, its industry, and its external environment. It uses a reasonable and feasible evaluation system to assess the environment the enterprise is faced with, adopts targeted and localized means to analyse it, and then mobilizes the superior resources of the enterprise to make strategic decisions.

\subsubsection{Strategic management options}

The strategic choice is based on the results of the strategic management analysis. The importance of strategic management analysis also stems from its role as a "cornerstone" and strategic choice is directed towards the formulation of strategic plans based on the results of strategic analysis [4]. Within the enterprise, the resource constraints, the feasibility of strategies between departments, and the goals and mission of enterprise development must be taken into account. Secondly, it is necessary to evaluate the scheme. The research and discussion method can better collect the strengths of hundreds of enterprises, discuss and complement the selected strategic scheme, and find the scheme that is more suitable for the development of the enterprise. Finally, the final choice of strategic management is made. The choice of strategic management is only completed at the end of this process.

\subsubsection{Implementation of strategic management}

The implementation of strategic management is the ultimate embodiment of all theoretical foundations. Strategic analysis and strategic choice ultimately serve to implement the strategy. Each point of the strategic proposal should be reflected in strategic management, including an effective organizational structure, the establishment of a staff appraisal system, an echo of strategic direction and corporate culture. Focus on key competitiveness and sustainable business development. At the same time, provided that the long-term strategy does not change arbitrarily, discuss the new strategy and direction of development in a timely manner according to the various factors they face in the short term.

\subsubsection{Strategic management evaluation}

The evaluation of strategic management is based on the results of the implementation of strategic management and has the function of "looking ahead and looking back". However, many enterprises ignore strategic management evaluation because of the desire to shorten the process. In fact, it rather corresponds to the summary of the work in this stage and the direction of the development of the work in the next stage, which is conducive to promoting the further development of the enterprise. 


\section{Development background and current situation of strategic management}

\subsection{Development background}

At present, the background of strategic management development is becoming more and more complex due to frequent economic activities and rapidly improving economic base, which are among the macro factors. We cannot change the adverse effects of macro factors, but we can take positive countermeasures to weaken their adverse effects on us. The integration of the current background faced by enterprises and the in-depth analysis of the background of strategic management development will help to realize further research on the strategic management of start-ups in the new era.

\subsubsection{Globalization background}

Market globalization, rapid development of enterprises has brought opportunities to developed countries and also expanded overseas markets. These enterprises have been affected by internationalization. Domestic development strategies gradually evolved into multinational strategies and these evolved into globalization strategies and factory separation. It was possible to establish a global arrangement with institutions, promote the coordinated integration of mutual resource utilization, promote the development of the local economy while the enterprises boomed, and ensure the favorable position of state finance to benefit from the global market and global enterprises. Governments of various countries have relaxed restrictions on economic activities in the region and gradually removed antagonism and alienation in politics and culture. The government has also played an active management role. In the case of the intermingling of government and enterprise, the business environment of the enterprise has gradually changed [3], and this has led to the adjustment and reform of the strategic management of the enterprise.

\subsubsection{Competitive increase}

The most obvious situation brought about by the global economy is the fierce competition among enterprises, so the measures taken by enterprises to respond quickly to this competition and the interpretation of innovation requirements have become an important direction of the organization of strategic enterprise management. Especially in the pandemic, it is more necessary for enterprises to continuously conduct business operations and complete innovation work in order to accelerate the response to specific problems [5]. As mentioned above, the rapid economic changes brought by the global market are followed by rapid environmental changes. The impact of macro factors is undoubtedly severe for businesses, and the speed of awareness of these impacts determines the speed of strategic adaptation of the enterprises. The second reason is the actions that need to be taken, whether to continue to expand scale, increase market share, or adopt a conservative strategy, which will affect the later direction of the business.

\subsubsection{Dynamic environmental factors}

The global economy, strong competition and technological development have created dynamic environmental factors for businesses [6]. "Dynamic" is relative to "static". Under the combined effect of the above three factors, "opening up" and "transformation" have become the main themes and focus of enterprise development strategy, and these factors will continue to promote social and economic transformation. This leads to a dynamic change in the social environment in which these enterprises find themselves. With the continuous improvement of openness, the "barriers" between countries are gradually breaking down, the boundaries of enterprise development are gradually blurring, international interaction is also improving, the possibility and practicality of political, economic and cultural exchanges between countries is increasing, and some advanced technologies can be used more widely. The business environment of enterprises around the world is therefore changing dynamically.

\subsubsection{Promotion of science and technology}

The promotion of science and technology has been integrated into all areas of our lives. Thanks to technological progress, transport and information communication are constantly developing [6]. Technological advances have shortened the "distance" between countries and businesses, and the concept of the "global village" has come to fruition. Although the distance between two countries is still very short geographically, with the advancement of communication technology, communication between two countries is no longer as difficult as before, and people's offices are not limited to office space. Using mobile phones, it is possible to surf the Internet and work anytime and anywhere, receive work messages, process office documents, etc. For businesses, this fast office mode poses a challenge to their own strategic management: competitors in the same sector are trying to do better, so what should be our strategic deployment? What is the positive role of science and technology for the development of our businesses today? How can we use it to connect with the trend of the times? All these factors need to be taken into account in strategic management. 


\subsubsection{Need for social responsibility}

As already mentioned, the rapid development of start-ups is intrinsically linked to the support of national policies. With the rapid rise and development of start-ups in line with the trend of the times, the relationship between government and enterprises is becoming increasingly close. The role of government must be naturally accepted by enterprises in order to promote social justice, ensure employment and accelerate economic construction. Therefore, the government can achieve some cooperation with enterprises [7], for example, by issuing relevant regulations. When enterprises help share the burden of "jobs", they can enjoy certain tax incentives. Therefore, businesses may have the problem of "increasing costs due to recruitment beyond their own development needs". Although it has been argued that a simple recruitment mechanism is more beneficial to corporate strategy, the surplus of labour and the need for high social responsibility will bring some difficulties in formulating corporate strategy and financial pressure, especially when social responsibility is mandatory, enterprises may need to consider how to bear social responsibility in strategy formulation [8].

\subsection{Development status}

Due to the impact of global economy, the intensity of competition has increased. The situation enterprises face in the dynamic environment is complex and fast-moving. The combination of science, technology and social responsibility also promotes the increase of factors that enterprises need to consider when formulating strategies. Under the new situation, corporate strategic management is facing the following status.

\subsubsection{The strategic direction tends to internationalization}

In formulating a strategy, the focus should be on the transnational or global economic market rather than just the domestic market. The speed of regional economic integration is increasing rapidly. More and more companies are penetrating foreign markets to gain greater market share and economic benefits. This behaviour of expanding its own market must take full account of the fact that the enterprise is formulating its own internationalisation strategy. For example, the enterprise must consider the branches, subsidiaries or offices to be established in different regions of the international market, and the "recruitment and management of employees" strategy, "risk management and control" strategy [9], "cost and control" strategy caused by this problem. We must focus on the trend of nationalization, understand the research of internationalization as the background, formulate appropriate strategies, and smoothly implement the development of enterprise internationalization.

\subsubsection{Strategic subjects tend to be diversified}

The diversification strategy refers to the strategy of selectively developing other businesses so that the business does not get into trouble because of the development of a single industry. Diversification strategy is related to specialisation. Specialisation is the focus of an enterprise on a particular product, which is an inevitable way to lay the foundations at an early stage of enterprise development. As the development of enterprises, products enter the maturity period, it is necessary to further explore the market. Therefore, the development of new products and the search for new markets becomes the only way. It can be seen that diversification is a possible way of operation, but it cannot be temporary but a comprehensive and long-term strategic behaviour of the enterprise. The main components of a diversification strategy are product diversification, market diversification, investment area diversification and capital diversification. Product diversification means that an enterprise operates two or more products or services simultaneously. Market diversification means that the enterprise's products are dispersed in multiple markets such as domestic market and international market. Regional diversification of investment means that the enterprise's investment activities are in different regions. Capital diversification means the diversity of enterprise capital, such as cash, machinery and equipment, factories, securities, intellectual property rights and trademarks.

\subsubsection{The implementation of the strategy tends to be strict}

Strictness is embedded in the strategy implementation process. After strategic analysis and decision-making, the subsequent strategic management is the key content of the entire implementation of the company's strategy. Therefore, how to ensure successful strategy implementation, how to link enterprise strategy to development, and how to support the realisation of enterprise objectives in strategic decision-making must be included in the scope that should be considered in the actual strategy implementation situation at this stage. Therefore, enterprises will take strategy implementation as an important part of the evaluation when evaluating the development performance of enterprises, and establish a topdown evaluation standard to include enterprise employees in the evaluation process, supervise employees, and motivate employees to promote strict strategy development through strict strategy implementation procedures. The company's overall strategy is big and broad, but the specific strategy broken down by overall strategy is the responsibility of the manager or department. [1] 


\section{The development process of strategic management of chinese start-up enterprises}

Since the reform and opening-up, China's economy has adapted to the trend of the times, continuously reformed its own development path, and finally achieved dazzling achievements. At present, China's economic development is characterized by diversified development, intelligence and innovation. There is no doubt that the continuous progress and development of enterprises have played a solid role in the process of rapid growth and can make solid progress in the fast-growing economic development. It can be said that the strategic management of Chinese enterprises plays an important role. Strategic management pays more attention to the competitive advantage, development status and value creation of enterprises in the industry, so it has become an important influencing factor and the way to realize the development of business enterprises in the new era.

\subsection{Germination and production}

The strategic management of Chinese enterprises is beginning to emerge since the reform and opening-up period. The process of its development is an important embodiment of China's reform and opening-up. Prior to reform and openingup, the planned economic system severely constrained the development of China's economy. At this time, enterprises did not have the right to operate independently, so they did not have the basic conditions for formulating strategic enterprise management, and it was impossible for enterprises to formulate, implement and evaluate strategies. It was only in 1978 that a series of important conferences were held, which gradually loosened the "autonomy" of enterprises, providing a background for the practice of strategic management of Chinese enterprises. With the issuance of a series of standards, industrial enterprises first explored the reform of the enterprise system, began to comply with relevant laws and regulations, and began to enjoy the autonomy of operation and management under the unified guidance and plan of the state, At this time, enterprises also began to explore the "management of their own enterprises"[10]. In 1984, the General Assembly proposed to "expand the autonomy of enterprises" and "enhance the viability of enterprises". By promulgating a series of legislation, it took the improvement of "expanding enterprise autonomy and promoting enterprise development" as its main goal. At this time, a series of researches on management methods for enterprise development began to appear. Many enterprises, such as Qingdao Refrigerator Factory (now Haier Group) and Sichuan Changhong (now Changhong Group), took the lead in introducing advanced management methods such as total quality management, realizing the improvement of enterprise management level and strategic enterprise management, which first entered people's consciousness at this time. At this stage, China's enterprise system exploration is not only the embryonic stage of strategic enterprise management, but also the exploration stage. It has brought some experience for the later practice of enterprise self-management and has a certain role in its promotion.

\subsection{Development and determination}

After the reform and opening up, strategic corporate governance achieved some development, but at this time the status of a market economy had not yet been fully established. At the initial stage of knowledge of strategic enterprise management, compared with Western countries, there is still a large gap in practice and research, and the relevant management system, strategy formulation, organizational framework and talent building are still immature. However, the introduction of enterprise autonomy still provides a great impetus for strategic enterprise management, provides a solid foundation for strategic management in the development of the enterprise in the new era, and makes an excellent contribution to the establishment of a modern enterprise system. In enterprise practice, a number of new pilot projects have emerged to promote the reform of state-owned enterprises, and enterprise forms such as alliance, merger and leasing have also appeared for the first time. In the process of reform, development needs have promoted the change of the internal organizational structure of enterprises. From the early 1990s, Chinese enterprises began to set up "strategic management" or "strategic planning" departments, such as the "strategic corporate development and investment committee" established by Tsingtao Beer in 1999 [1]. The existing practice of strategic management of Chinese enterprises has begun to penetrate into other enterprises. Businesses have realized the importance of strategic management and its indispensability to the development and planning of the economy. The practice of enterprise strategic management has also stimulated a huge demand for theory and talents, and the evaluation of employees is also based on the introduction of the idea of enterprise strategic management. It also directly encourages the cultivation of talents. Major universities have adopted "strategic management" as a separate discipline for the professional training of students.

\subsection{Growth and present}

After the establishment of market economy status and after long and continuous practice and examination, the research on the management of Chinese enterprises in the Warring States period has made great progress. Against the background of globalization, the introduction of some Western ideas has had an obvious illuminating and illuminating effect on the enterprise strategy of Chinese countries, and the strategic management of Chinese enterprises has entered a new period of growth. Under the influence of a series of documents and policies, such as management methods and development strategies, strategic enterprise management has started the peak of rapid growth and development. Chinese strategic enterprise management has gradually evolved from domestic development to international direction. Under the challenge 
and support of policies, Chinese enterprises gradually strengthened their understanding of "strategy", began to formulate strategies in accordance with their own development according to their own actual situation, and widely engaged in more intense, complex and changeable international competition. In addition, entrepreneurs actively participate in various forums where they exchange experiences and knowledge on corporate strategy formulation and strategic practice. By learning from the advanced models of other businesses, they broaden their own thinking and vision. A large number of Chinese enterprises have gradually "set sail", entered the wider global market and gradually become an important force and part of the international market and international competition. In continuous practice, we have acquired advanced technology, resources and management experience.

\section{Strategic analysis of midea group co., Itd}

In this chapter, the author uses quantitative analysis method to analyse the strategy of Midea Group, makes vertical comparison of financial statements of different years, analyses the influence of corporate strategy on Midea Group, and evaluates its strategic model.

\subsection{Midea enterprise and strategy}

The Midea Group entered the air conditioning industry in 1985 and began to explore new categories in the home appliance sector. In 2013, Midea was listed on the Shenzhen Stock Exchange. In 2020, Midea Group's stock price reached a record high of 94.76 yuan, up 2453\% from the opening price of 3.7 yuan on September 18, 2013; in 2020, it ranked 288th on the Fortune Global 500; on December 24, Midea acquired Hitachi's compressor factory in Thailand and disrupted the global industry. Faced with the development of a new era, Midea has adopted a diversification strategy, and now it has obvious effects. Midea has been pursuing a diversified strategy for more than a decade. In 2018, Midea's market share was $27 \%$, rising to $29.5 \%$ in 2019 , with an outbreak at the end of 2019 . Therefore, in 2020 , most enterprises faced the problem that their products could not be sold and most of the goods were piled up in warehouses However, the market share of the Midea Group at the end of 2020 not only did not decline, but increased to 34.5\%, which is $8.5 \%$ more than in 2019, indicating that the multi-year diversification strategy of the Midea Group has borne fruit in early 2020. Therefore, the Midea Group can maintain its market share in 2020 even if the overall environment is affected by the epidemic These figures show that a diversification strategy can bring economic benefits to businesses (Data source: Midea Group Financial Statements 2018-2020)

\subsection{Financial analysis of Midea Group}

\subsubsection{Analysis of profitability}

Table 1. Profitability data (Unit: Million yuan)

\begin{tabular}{|l|c|c|c|}
\hline & 2018 & 2019 & 2020 \\
\hline Gross revenue & 261,820 & 279,381 & 285,710 \\
\hline Operating profit & 25,564 & 29,683 & 31,493 \\
\hline Net margin & 21,650 & 25,277 & 27,507 \\
\hline $\begin{array}{l}\text { Year-end cash and } \\
\text { cash equivalents }\end{array}$ & 17,952 & 30,442 & 23,549 \\
\hline
\end{tabular}

Source: Midea Group annual Report 2018-2020.

The profit data of Midea Group from 2018 to 2020 are shown in Table 1. From 2018 to 2020, the total operating income, operating profit and net profit of Midea Group kept growing continuously. The year-end cash and cash equivalents balance both fluctuated slightly in 2020, but still kept growing on the whole.

Table 2. Profitability indicator data (Unit: Percent)

\begin{tabular}{|l|c|l|l|}
\hline & 2018 & 2019 & 2020 \\
\hline $\begin{array}{l}\text { Gross profit } \\
\text { margin }\end{array}$ & 27.54 & 28.86 & 25.11 \\
\hline $\begin{array}{l}\text { Net operating } \\
\text { interest rate }\end{array}$ & 8.34 & 9.09 & 9.68 \\
\hline $\begin{array}{l}\text { Returns on gross } \\
\text { assets }\end{array}$ & 8.2102 & 8.3712 & 7.6326 \\
\hline
\end{tabular}




\begin{tabular}{|l|l|l|l|}
\hline $\begin{array}{l}\text { Net profit margin } \\
\text { on sales }\end{array}$ & 8.3378 & 9.0854 & 9.6779 \\
\hline Return on equity & 24.35 & 23.81 & 23.17 \\
\hline
\end{tabular}

Source: Midea Group annual Report 2018-2020.

Table 2 shows the profitability index data of Midea Group from 2018 to 2020. From the perspective of profitability index, net operating profit margin on sales increased steadily during this period, indicating that the business situation of the enterprise was good, and the gross profit margin on sales also maintained a stable level during the pandemic. Although the profit margin on total assets declined in 2020, the fluctuation range was relatively small, indicating that the operation status of the enterprise was relatively stable. The fluctuation of return on net assets was relatively small, but the level was relatively high, achieving about three times the profit margin on total assets, indicating that the enterprise was highly profitable

\subsubsection{Financial risk analysis}

Table 3. Risk Financial Data (Unit: Percent)

\begin{tabular}{|l|c|c|c|}
\hline & 2018 & 2019 & 2020 \\
\hline Current ratio & 1.4028 & 1.5 & 1.3123 \\
\hline Cash Ratio & 21.4145 & 49.1391 & 44.1001 \\
\hline $\begin{array}{l}\text { Debt to Asset } \\
\text { Ratio }\end{array}$ & 64.9397 & 64.4 & 65.5263 \\
\hline Equity ratio & 175.5701 & 172.6731 & 182.6973 \\
\hline
\end{tabular}

Source: Midea Group annual Report 2018-2020.

Data on the solvency and capital structure of the Midea Group are presented in Table 3. If the liquidity ratio is higher than 2, the assets of the enterprise can be converted into cash of the year need to pay twice the liabilities of the Midea group due to the nature of the production of goods, the current ratio is less than 2, but in recent years the change in amplitude is small, less affected by the impact of the epidemic. In addition, Midea Group's cash ratio, equity ratio, assetliability ratio have been steadily increasing, indicating that Midea Group's financial risk level is relatively low and can maintain stability despite the impact of the pandemic.

\subsubsection{Operational capability analysis}

Table 4. Operational capability analysis. Unit: Percent

\begin{tabular}{|l|c|c|c|}
\hline & 2018 & 2019 & 2020 \\
\hline $\begin{array}{l}\text { Accounts receivable } \\
\text { turnover }\end{array}$ & 14.0668 & 14.6222 & 13.6506 \\
\hline Inventory turnover & 6.3688 & 6.3725 & 6.7015 \\
\hline Total assets turnover & 1.0147 & 0.9837 & 0.8582 \\
\hline
\end{tabular}

Source: Midea Group annual Report 2018-2020.

Table 4 shows that the Midea Group's accounts receivable turnover has decreased in 2020, indicating that the company's recovery rate has slowed down, which is related to the pandemic outbreak in 2020. The Midea Group's customers and suppliers are in a non-saleable phase and do not have sufficient funds to repay their liabilities. From the perspective of inventory turnover rate, the Midea Group's inventory turnover rate is still higher from 2018 to 2020 , indicating that the enterprise has made some achievements in inventory management and improved performance management. From the perspective of fixed asset turnover rate analysis, the Midea Group's fixed asset turnover rate has been decreasing year by year, but it is still at a stable level, indicating that the utilization of fixed assets is relatively appropriate.

\subsection{The influence of enterprise strategy on enterprise operation}

The above analysis shows that the implementation of appropriate strategies contributes to the long-term development of businesses, which can maintain their key competitiveness even in the face of a widespread economic downturn [6]. The diversification strategy adopted by the Midea Group as an outstanding enterprise in the home appliance sector can 
help its long-term development. However, many enterprises have not realized that they have adopted an adequate strategy in the early stage of development, or there is no corporate strategic awareness, and most enterprises still have some problems in strategic management in the new era.

\section{Problems in strategic management of start-up enterprises in the new era}

Although start-up enterprises have the advantages of obvious political support and strong innovation ability, in the face of the rapidly developing and changing economic system and the industrial constraints of large enterprises, small enterprises still need to comprehensively assess the internal and external environment, and then constantly improve their strategic system in combination with their own advantages and disadvantages. When seeking the complete construction of the strategic system, we should take into account the favourable development of the enterprise.

\subsection{Ignoring the overall situation of strategic management, strategic objectives and strategic planning are unrealistic}

When formulating strategic management of an enterprise, most enterprises cannot look at the future development of enterprises from a long-term perspective. This phenomenon is especially common in start-ups, mainly because start-ups do not have their own positioning, vision and goals established in the early stage of development [11]. All their business development is focused on one inspiration and have not improved their other contents such as lack of organizational structure framework. Slow scale development caused by lack of capital support limits the overall grasp of strategic management by start-ups. In addition, start-ups are busy gaining a competitive position at an early stage of development, so they often ignore the content of 'strategy'. What entrepreneurs need is only a quick entry of capital, not the formulation of a specific enterprise goal. Therefore, even management is faced with the phenomenon of coping with the formulation of strategic management. It only displays relevant content in the report to accomplish a certain task, that's all. Even some enterprises have not introduced the idea and concept of "strategy".

\subsection{Pay no attention to human security, post setting and other factors}

As mentioned above, CSR commitment will lead to increased corporate costs. However, an equally important issue is how to ensure that employees can get full protection of their rights and get the pay they should get for their work. When reducing costs, companies usually consider: reducing employee wages, cutting holidays, reducing the number of jobs, etc.; however, this does not necessarily lead to strategic corporate governance. On the contrary, in the short term, costs are reduced, but in the long term, employees are in a low-motivation work environment and their performance is not high. Even the general principles of the company are no longer followed. In addition, when recruiting employees, we should also match the quality of employees with the needs of the jobs. This demand-driven recruitment strategy is often more effective.

\subsection{Wrong judgment of the economic environment}

Either an overestimation of the economic environment or a poor assessment of it makes it difficult for companies to make a proper analysis of the objective situation. In the early stage of business, enterprises often have great ambitions, but do not take into account the speed or complexity of today's economic development, easily get lost in the flow of the economy, misjudge the market environment, and thus it is difficult to develop scientific strategic objectives and planning. In the wake of the pandemic, it is all the more important that businesses rethink the steps they can take to help themselves in times of economic uncertainty [11].

\subsection{Untimely strategic adjustment}

Although a company's strategy is comprehensive and long-term, if the company faces drastic changes and the company's strategy no longer suits the current development of the company, it is necessary to integrate various factors and adjust the company's strategy. Generally speaking, the formulation, implementation and evaluation of an enterprise strategy is a long-term and time-consuming process. During this time, enterprise managers should conduct a comprehensive analysis of the current situation of the enterprise [12]. If there are differences before and after the analysis, they should make strategic adjustment in time. However, if this factor is ignored, it will lead to the wrong formulation of enterprise strategy and various problems in its implementation. On the other hand, the enterprise strategy is formulated. If the results of strategic evaluation are not corrected and adjusted in time, the development direction of the enterprise will gradually move away from the strategic goal. 


\section{Conclusion}

A diversification strategy can improve the ability of enterprises to withstand risks and can help enterprises to develop quickly after a risk and to recover previous levels of development. Therefore, enterprises should consider the following factors when carrying out strategic management and judge whether the enterprise is suitable for diversification strategy according to its own situation.

\subsection{Considering the overall situation of strategic management, formulation of practical strategic objectives and strategic planning}

With the rapid economic development, the problem that every business faces is whether to continue to stick to the strategy it has set or to change it according to the market situation. However, the answer is not the same for all businesses. Therefore, enterprises should comprehensively consider the changes and development trend of their industry. For example, in the context of intelligence, if the home appliance industry still sticks to the industry as before without changing and upgrading the embedded core technology, it will only lose market share under the pressure of the industry. Therefore, when formulating business strategy, enterprises should focus on the development trend of the future world and formulate strategies in accordance with their own development according to their own industry. Comprehensively consider the organizational framework, performance incentives and other factors to establish their own core competitiveness. In addition, when formulating strategic planning, we should also consider long-term strategic goals, and not only see the immediate interests, because in the era of rapid development, the risks of enterprises often appear in the form of "they were out before they were ready for change" [3]. Therefore, it is important for enterprises to accurately assess the direction of their industry when formulating strategic management.

\subsection{Pay attention to human security, post setting and other factors}

Due to the lack of their own financial capacity, start-ups often ignore some potential influencing factors. For example, when formulating strategic management, we do not pay attention to talent recruitment and consistent post setting, which will lead to unclear division of internal responsibilities and unclear definition of responsibility scope. When formulating enterprise strategic management, we should have the idea of "recruiting talents", train professional talents, place them in suitable posts, and give them a salary guarantee system matching their ability to ensure that they can concentrate on serving the company. In addition, the need for social responsibility should be taken into account. In the initial stage, startups often have close cooperation with the government. Therefore, while undertaking social responsibilities, they will bring various benefits such as tax relief and promotion, and can improve the corporate image and expand the popularity of enterprises to a certain extent. The form of cooperation with the government will also be deeply recognized by consumers, which can increase their competitiveness.

\subsection{Fully understand their own economic environment}

The economic environment in which a company is located is one of the important factors in formulating a company's strategy. However, if it does not timely interpret the internal and external environment of the corporate environment and identify the opportunities brought by the new era, it will miss the opportunity. Therefore, when formulating strategies, managers should timely understand the data brought by the economic market, analyse the risks and challenges brought by the current economic environment with the data, and then decide whether to use expansionary or conservative strategies and formulate their own development strategies based on the data $[13,14]$. Now in the complex economic background, there is a need not only to specialize in a particular product or service, and develop another product line to increase its competitiveness. The diversification strategy of the enterprise widely used, and from a certain degree, it is not only about the effective use of surplus capital, it is about the enterprise's own competitiveness.

\subsection{Timely strategic assessment and strategic adjustment}

First, the current strategy needs to be adapted to the results of the last strategic assessment. The result of the last strategic assessment is feedback on the implementation of the company's strategy in the previous phase, thanks to which the current process and direction of the company's development can be clearly understood. Therefore, it is an important element that the enterprise must pay attention to. In addition to the overall evaluation of strategy implementation, there is also a strategic evaluation of a specific stage or department, which should also be given special attention. If a start-up wants to achieve sustainable development, all aspects of strategic management should cover the entire development of the enterprise. It should always be based on the 'strategy', evaluating the direction of the stage and monitoring whether it deviates from the overall strategic development objective or still meets the requirements of current economic development. In addition, it is necessary to establish a special Strategic Management Department. In establishing it, it is necessary to select personnel with work experience and good understanding of the enterprise, always pay attention to the changes in the form of the new period, and evaluate and formulate the strategic management of the enterprise. 


\section{References}

1. A. Tripathi, T. Bagga, S. Sharma, S. K. Vishnoi. Big Data-Driven Marketing enabled Business Performance: A Conceptual Framework of Information, Strategy and Customer Lifetime Value. 11th International Conference on Cloud Computing, Data Science \& Engineering (Confluence). 11, pp. 315-320 doi: 10.1109/Confluence51648.2021.9377156 (2021)

2. R. J. Baumgartner, R. Rauter. Strategic perspectives of corporate sustainability management to develop a sustainable organization. Journal of Cleaner Production. 140, 81-92 (2017)

3. N. Pröllochs, S. Feuerriegel. Business Analytics for Strategic Management: Identifying and Assessing Corporate Challenges via Topic Modeling. Information \& Management. 57(1) (2018)

4. Z. Zhong, W. Haoran, W. Junsheng. Analysis of Enterprise Strategic Management Issues and Coping Strategies Based on Big Data Analysis. E3S Web of Conferences. 214, 01017 (2020)

5. M. Meng, S. Saide, S. Ratna, M. Muflih. Business Continuity Innovation in Disruption Time: Sociotechnical Systems, Business Analytics. Virtual Business, and Mediating Role of Knowledge Absorptive Capacity. IEEE Transactions on Engineering Management. 1-12 (2021)

6. M. H. Shekhar, M. Raihan, R. Sunanda, M. Sabyasachi. Effective Business Strategy Decision Making Method Using Fuzzy Logic. IEEE 2018 9th International Conference on Computing, Communication and Networking Technologies (ICCCNT). 1-4 (2018)

7. Y. Liu, L. Peng, T. Lin, Ee. Dong. Research on Ctrip Corporate Social Responsibility Strategy: An Empirical Case. 2021 7th International Conference on Information Management (ICIM). 172-76 (2021)

8. E.-M. Vătămănescu, D.-C. Dabija, P. Gazzola, J. G. Cegarra-Navarro, T. Buzzi. Before and after the Outbreak of Covid-19: Linking Fashion Companies' Corporate Social Responsibility Approach to Consumers' Demand for Sustainable Products. Journal of Cleaner Production. 327, 129465 (2021)

9. J. H. de Oliveira, C. M. de Lima, N. F. Almeida, A. M. Mariano, A. C. Bittencourt Reis, J. M. da Silva. Costs influence and mediating effect of corporate risk management on organizational performance: a study applied to the Brazilian Public Service," 2021 16th Iberian Conference on Information Systems and Technologies (CISTI). 1-6 doi: 10.23919/CISTI52073.2021.9476392 (2021)

10. X. Erming, L. Weiguang. Strategic Management of Chinese enterprises in the past 40 years (1978-2018): Review, Summary and Prospect [J]. Economic and management research. 39(09), 3-16 (2018)

11. T. Malviya. A multi-dimensional business strategy model for effective decision making: A holonic representation of enterprises. 2017 IEEE International Systems Engineering Symposium (ISSE). 1-6 doi: 10.1109/SysEng.2017.8088297 (2017)

12. Z. Ping. Manager Interaction and the Formation of Strategic Consensus: The Moderation Effect of Manager Role. Science Innovation. 7(4), 115-119 doi: 10.11648/j.si.20190704.12 (2019)

13. M. Borges, J. Bernardino, I. Pedrosa. Data-driven decision making strategies applied to marketing. 2021 16th Iberian Conference on Information Systems and Technologies (CISTI). 1-7 doi: 10.23919/CISTI52073.2021.9476506 (2021)

14. A. Najdawi, S. K. Patkuri. Modeling Business Intelligence Process: Toward Smart Data-Driven Strategies. 2021 International Conference on Computational Intelligence and Knowledge Economy (ICCIKE). 198-202 doi: 10.1109/ICCIKE51210.9410804 (2021) 